\title{
Enhanced Direct Power Control Strategy of a DFIG-Based Wind Energy Conversion System Operating Under Random Conditions
}

\author{
Younes Sahri ${ }^{1}$, Salah Tamalouzt ${ }^{1}$, Sofia Belaid Lalouni ${ }^{1 *}$ \\ ${ }^{1}$ Laboratoire de Technologie Industrielle et de I'Information (LTII), Faculté de Technologie, Université de Bejaia, 06000 Bejaia, Algeria \\ * Corresponding author, e-mail: sofia.lalouni@univ-bejaia.dz
}

Received: 13 June 2020, Accepted: 24 September 2020, Published online: 07 June 2021

\begin{abstract}
The main objective of this paper is the performances analysis of an Enhanced Direct Power Control (EDPC), applied to Doubly Fed Induction Generator (DFIG) driven by variable speed Wind Turbine (WT). This control strategy uses hysteresis regulators and switching table for active and reactive powers control. These latter are estimated using rotor currents and grid voltages instead of a traditional measurement of stator currents. In addition, the EDPC switching table is based on the position of the rotor flux instead of the stator flux in order to have better regulation accuracy because the rotor voltage vector directly influences the rotor flux and has a proportional relationship with the active and reactive powers. All the operating modes (sub-synchronous, super-synchronous, synchronous and over-speed) of the variable speed WT-DFIG system and the possibility of local reactive power compensation are reported and discussed in this paper. Depending on the operating zone of the WT, Maximum Power Point Tracking (MPPT) technique and pitch angle control are considered to optimize the wind energy efficiency. The validation of the proposed EDPC strategy has been performed through simulation tests under MATALB/Simulink, the obtained results show robustness and good performances with low THD of the generated currents.
\end{abstract}

Keywords

wind energy conversion, Doubly Fed Induction Generator (DFIG), Enhanced Direct Power Control (EDPC), generated active management, reactive power management, local reactive power compensation, Maximum Power Point Tracking (MPPT)

\section{Introduction}

The blue planet, the human and all living beings suffer from pollution, climate change and their consequences. This global issue kills more than 9 million humans every year, causes the extinction of various animals on earth and several diseases are caused by air pollution [1]. All those threats give Renewable Energy Sources (RESs) a great importance, quick and high technology development in recent few years to replace conventional sources. From all RESs, wind energy is the most important, the most growing and the biggest power exporter. It is used to produce electricity without any $\mathrm{CO}_{2}$ emissions using wind turbine conversion system [2].

For wind turbines (WTs), DFIG is widely used compared to other generators due to many advantages that it offers, especially for variable speed operation. The DFIG is an Induction Machine (IM) with both windings stator and rotor which are separated and connected to the grid.

Most studies use AC/AC converter only in the rotor side to control the generated powers, making the electronic power converters and power loss less than those of conventional full-size stator converters. The DFIG is able to operate under different modes (sub, super and synchronous modes), it offers also: decoupling control of active and reactive powers, operating in wide range of speed and ability to deliver a large amount of energy [2-3].

Due to the non-linear behavior of the WT, the DFIG and the power converter, several non-linear control techniques have been invested to improve the Wind Energy Conversion Systems (WECSs). The conventional control is based on Field-Oriented Control (FOC) [4] and Direct Control methods: (Direct Torque Control -DTCand Direct Power Control -DPC-). The FOC strategy is defined as an indirect control, which has been presented in different works [4-6]; it depends on machine parameters 
to design the PI controllers in the case of linear control. Also, it requires reference frame and PWM block modulation that make this method more complex. In the opposite, we find the direct control methods, such as DTC [7] and DPC [8-10]. Those methods are characterized by high performances, quick response drives and simplicity compared to FOC. They are based on the selection of optimal voltage vector using the voltage and current measurements and the switching table. Otherwise, many authors have presented other strategies of power control applied to DFIG; they also name them Direct Power Control. But in their contexts, they use indirect strategies to control the powers. Also, they have invested the SVM-DPC strategy by using PI regulators to calculate the optimal rotor voltage in $d$ - $q$ frame with utilizing the PWM block modulation, instead of the hysteresis regulators and the switching table; their strategies are different than direct control methods [11-13]. The DPC was introduced by $\mathrm{Xu}$ and Cartwright [8] in to control the stator active and reactive powers, generated by the DFIG. The principal of this technique is based on the stator active and reactive powers estimation and the stator flux position to select the optimal rotor voltage vector using a switching table.

The parameters estimations and the stator flux position are based on the synchronous pulsation $\left(\omega_{s}\right)$, the stator voltages and currents in $d-q$ synchronous frame. The use of stator flux in the power control made disturbances on the output voltage $V_{s}$ and frequency while the stator flux has to be constant $\left(\varphi_{s}=V_{s} / \omega_{s}\right)$ to guarantee a permanent connection of the wind generator to the $\mathrm{AC}$ grid, where the conditions of connection to the AC grid are: the same voltages, the same frequencies and the same succession of phases. On other side, the DPC suffers from many disadvantages, therefore, some authors have replaced the hysteresis regulators and the switching table by an artificial intelligence technique (Fuzzy Logic Control or Artificial Neural Network) [14-17]. Some other authors have used Multi-Level converter or Matrix converter instead of the classical two-level converter [18-20]. Moreover, a DPC combined with Sliding Mode Control (SMC) has been applied to a Multi-Level converter in [21]. Those contributions were made in order to reduce the THD, to increase the energy quality and to minimize the active / reactive power ripples. In addition, the SVM technique (SVM-DPC) is introduced to set a fixed switching frequency [11, 22]. Consequently, all those techniques mention in $[11,14-23]$ increase the complexity of the control system or require the knowledge of system parameters. Moreover, the DPC analyzed earlier [8, 11, 14-17, 20-24] are all based on the conventional strategy mentioned in [8]. In these references, the simulation results verify the system performances only in the sub-synchronous mode, reflecting the operation of an IM, under a small range of time and fixed power independently of the driving wind speed. This reflects that the main characteristic of the WT is not taken into account, knowing that the generated electrical power by such a system depends directly on the mechanical characteristic of the WT (speed and mechanical power). In addition, they don't exploit the most important DFIG's advantages: variable speed operation, control of generated active power and the reactive power management, except in $[18,25]$. In [18], the author has proposed a direct reactive power control under a large random wind profile without controlling directly the active power, where in [25] an Adaptive DPC has been invested to control WT-DFIG under a random wind speed. However, the presented results show high THD upper the limits imposed by IEEE Std 519, high active and reactive power ripples and a complex control system without treating all DFIG operation modes. In all [8, 10-17, 19-25], authors have controlled the reactive power in the stator side and not the local reactive power compensation $\left(Q_{A C}\right)$. This indicates that the advantages offered by the WT-DFIG are not taken into account. In this paper, we propose an EDPC strategy, applied to WECSs energy production, to control the generated active power and the local reactive power compensation of the WT-DFIG system. In the proposed strategy, the selection of the optimal rotor voltage vector is based on rotor flux position instead of stator flux position. This control will give more precision and quick response, because the power variations have direct relation with the rotor voltage and the rotor flux when the stator flux is kept constant. Another contribution in this work is the simplicity of estimating the generated active power, the local reactive power compensation and the rotor flux position, using only the measurement of rotor currents in $d$ - $q$ synchronous frame and considering an infinite AC grid. The good performances analysis of the proposed EDPC strategy is confirmed under a random behavior with a large range of wind speed profile and requirement local reactive power compensation, by taking into account all WT-DFIG operation modes: sub, super, synchronous modes and the over speed in successive and continuous manner, reproducing operation that approximates the real behavior of the wind 
turbine generator. The captured wind energy is optimized to extract the optimal power, below the nominal turbine speed using the MPPT algorithm and beyond we will be acting on the pitch angle control. Moreover, the energy quality delivered by the generator, as the generated currents, is also analyzed using Fast Fourier Transform (FFT), the recovered THD value is lower than the limit imposed by norm.

This contribution has never been treated in the literature, where the simplicity of control is conserved, the high power control precision is observed, the good power quality is provided, the satisfactory compensation of reactive power compensation according to the random $\mathrm{AC}$ grid demand is respected and above all DFIG's advantages are exploited under random behavior conditions. This control strategy is developed and validated under MATLAB/ Simulink.

\section{Description and modeling of the studied WT-DFIG system}

The studied WT-DFIG system with the proposed control strategy is presented in Fig. 1. The mechanical part of the system contains an aerodynamic turbine and a gearbox. The mechanical power is a function of the air density, the blade radius, the wind speed and the power coefficient, is denoted in $[25,26]$ as follow (Eq. (1)):

$$
P_{\text {mec }}=0.5 \rho \pi R^{2} v^{3} C_{P}(\lambda, \beta) .
$$

The power coefficient and the tip speed ratio are given by Eq. (2):

$$
\left\{\begin{array}{l}
C_{P}(\lambda, \beta)=C_{1}\left[C_{2}\left(\frac{1}{\lambda_{i}}\right)-C_{3} \beta-C_{4}\right] e^{\left(\frac{C_{5}}{\lambda_{i}}\right)}+C_{6} \lambda_{i} \\
\frac{1}{\lambda_{i}}=\frac{1}{\lambda+0.08 \beta}-\frac{0.035}{1+\beta^{3}}
\end{array} .\right.
$$

The mathematical model of DFIG in the $d-q$ synchronous frame is described as in Eq. (3) [26].

$$
\left\{\begin{array}{l}
V_{s d}=R_{s} i_{s d}+\frac{d \varphi_{s d}}{d t}-\omega_{s} \varphi_{s q} \\
V_{s q}=R_{s} i_{s q}+\frac{d \varphi_{s q}}{d t}+\omega_{s} \varphi_{s d} \\
V_{r d}=R_{r} i_{r d}+\frac{d \varphi_{r d}}{d t}-\omega_{r} \varphi_{r q} \\
V_{r q}=R_{r} i_{r q}+\frac{d \varphi_{r q}}{d t}+\omega_{r} \varphi_{r d}
\end{array}\right.
$$

As described in Eq. (3), the DFIG is an IM connecting by its stator directly to the AC grid, although the rotor is connected to two different power electronics converters. The first is an AC/DC converter controlled by the proposed EDPC strategy and the second is a DC/AC converter

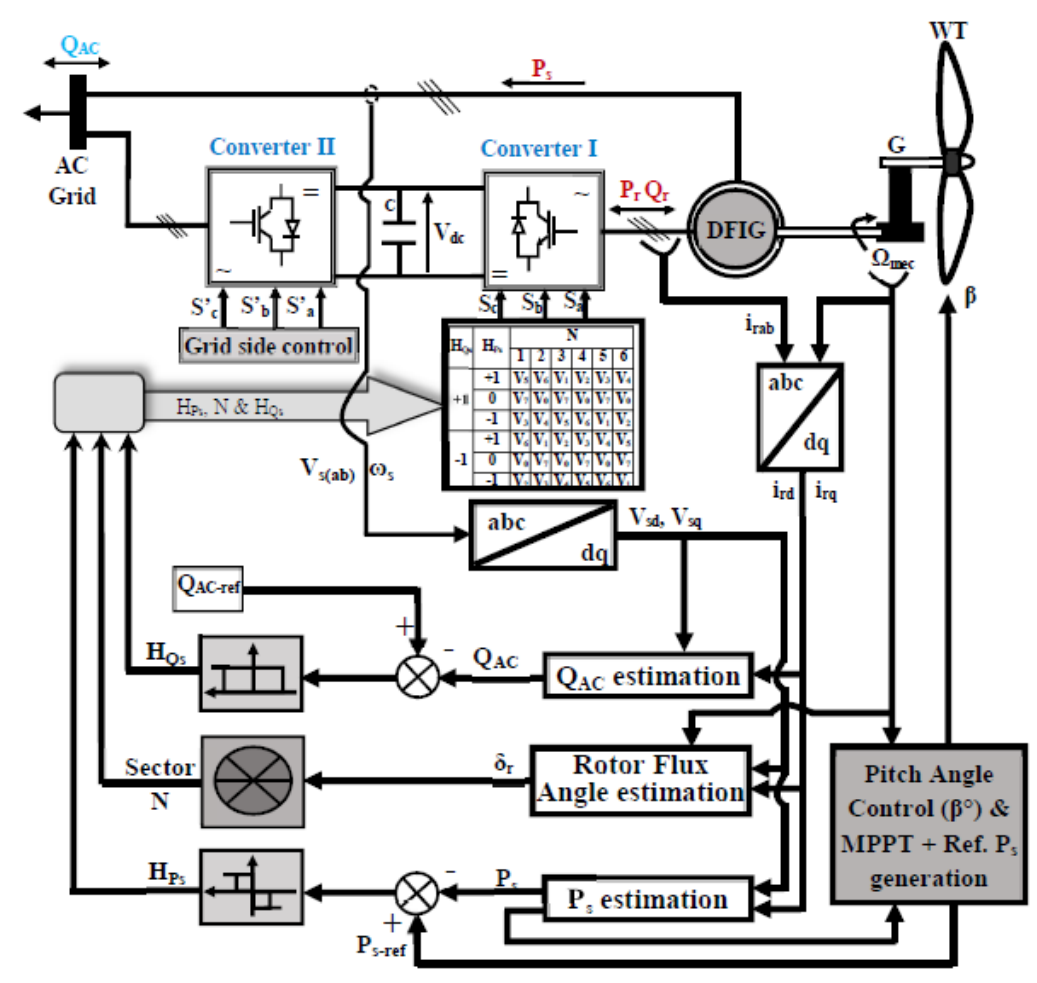

Fig. 1 The global WT-DFIG system controlled by the proposed EDPC strategy 
connected to the AC grid and controlled in manner to deliver a sinusoidal current with the AC grid frequency $(50 \mathrm{~Hz})$ and a null reactive power, which is fixed to have a unit power factor operation [18].

The DFIG magnetic flux equations in the $d-q$ synchronous frame are in Eq. (4):

$$
\left\{\begin{array}{l}
\varphi_{s d}=L_{s} i_{s d}+M i_{r d} \\
\varphi_{s q}=L_{s} i_{s q}+M i_{r q} \\
\varphi_{r d}=L_{r} i_{r d}+M i_{s d} \\
\varphi_{r q}=L_{r} i_{r q}+M i_{s q}
\end{array}\right.
$$

\section{EDPC description applied to the WT-DFIG system}

As described in [27], the WT can operate in different zones (Fig. 2). The system is controlled to extract the maximum power using MPPT algorithm [28, 29], when the generated power is lower than its nominal value. In zone II, called also over speed region, the generated output power is limited at its nominal value using pitch angle control in order to avoid any electrical or mechanical damage.

The proposed DPC principal is inspired from DTC, where the regulation of generated active power and local reactive power compensation is based on the optimal selection of voltage vector using power errors and rotor flux angle instead of stator flux angle.

According to the vector space theory, the instantaneous active and reactive powers can be expressed by Eq. (5) [27]:

$$
\left\{\begin{array}{l}
P_{s}=\operatorname{Re}\left\{\vec{V}_{s} \cdot \vec{i}_{s}^{*}\right\} \\
Q_{A C}=\operatorname{Im}\left\{\vec{V}_{s} \cdot \vec{i}_{s}^{*}\right\}
\end{array}\right.
$$

In addition, the active and reactive powers could be denoted as follow (Eq. (6)):

$$
\left\{\begin{array}{l}
P_{s}=V_{s \alpha} i_{s \alpha}+V_{s \beta} i_{s \beta} \\
Q_{A C}=V_{s \beta} i_{s \alpha}-V_{s \alpha} i_{s \beta}
\end{array} .\right.
$$

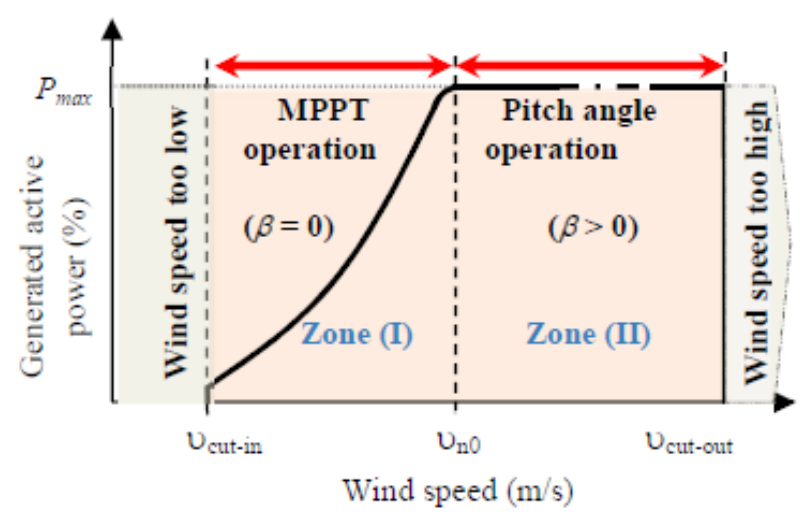

Fig. 2 Wind turbine characteristic
The stator voltages components in $\alpha-\beta$ rotor reference are given in Eq. (7):

$\left\{\begin{array}{l}V_{s \alpha}=R_{s} i_{s \alpha}+\frac{d \varphi_{s \alpha}}{d t}-\omega \varphi_{s \beta} \\ V_{s \beta}=R_{s} i_{s \beta}+\frac{d \varphi_{s \beta}}{d t}+\omega \varphi_{s \alpha}\end{array}\right.$.

The stator currents in the rotor frame are denoted as (Eq. (8)):

$\left\{\begin{array}{l}i_{s \alpha}=\frac{1}{\sigma L_{s}} \varphi_{s \alpha}-\frac{M}{\sigma L_{s} L_{r}} \varphi_{r \alpha} \\ i_{s \beta}=\frac{1}{\sigma L_{s}} \varphi_{s \beta}-\frac{M}{\sigma L_{s} L_{r}} \varphi_{r \beta}\end{array}\right.$

Where the coefficient of dispersion $\sigma$ of the DFIG provided by: $\sigma=1-\frac{M^{2}}{L_{S} L_{r}}$

In addition, the stator flux in the rotor frame is given as follow in Eq. (9):

$\varphi_{s}=\left|\varphi_{s}\right| e^{j \theta_{r}}$.

By replacing Eqs. (7-9) in Eq. (6), the powers relationship will be (Eq. (10)):

$\left\{\begin{array}{l}P_{s}=-\omega_{s} \varphi_{s \beta}\left(\frac{1}{\sigma L_{s}} \varphi_{s \alpha}-\frac{M}{\sigma L_{s} L_{r}} \varphi_{r \alpha}\right) \\ +\omega_{s} \varphi_{s \alpha}\left(\frac{1}{\sigma L_{s}} \varphi_{s \beta}-\frac{M}{\sigma L_{s} L_{r}} \varphi_{r \beta}\right) \\ Q_{A C}=\omega_{s} \varphi_{s \alpha}\left(\frac{1}{\sigma L_{s}} \varphi_{s \alpha}-\frac{M}{\sigma L_{s} L_{r}} \varphi_{r \alpha}\right) \\ -\omega_{s} \varphi_{s \beta}\left(\frac{1}{\sigma L_{s}} \varphi_{s \beta}-\frac{M}{\sigma L_{s} L_{r}} \varphi_{r \beta}\right)\end{array}\right.$

Then $P_{s}$ and $Q_{A C}$ will be expressed as described in the following Eq. (11):

$$
\left\{\begin{array}{l}
P_{s}=-\frac{M}{\sigma L_{s} L_{r}} \omega_{s}\left|\varphi_{s}\right|\left|\varphi_{r}\right| \sin \gamma \\
Q_{A C}=\frac{\omega_{s}}{\sigma L_{s}}\left|\varphi_{s}\right|\left(\frac{M}{L_{r}}\left|\varphi_{r}\right| \cos \gamma-\left|\varphi_{s}\right|\right)
\end{array}\right.
$$

As the DFIG is connected directly to a balanced AC grid, the stator flux $\left|\varphi_{s}\right|$ has a constant value, so the generated active and the local reactive power compensation variations $\left(\Delta P_{s}, \Delta Q_{A C}\right)$ depend on the rotor flux variations $\left(\Delta \varphi_{r}\right)$ and the angle between $\varphi_{s}$ and $\varphi_{r}(\gamma)$. 
According to Faraday's law, the rotor flux is given by Eq. (12):

$\varphi_{r}(t)=\int_{0}^{t}\left(v_{r}-R_{r} i_{r}\right) \mathrm{dt}$.

Moreover, between tow inverter commutations, the rotor voltage vector will have the same value magnitude with different direction. The rotor voltage drop can be neglected compared to $V_{r}$, so the equation will be simplified as in Eq. (13):

$\varphi_{r}(t)=\varphi_{r}(0)+v_{r} \Delta T$.

From the Eq. (13), we can describe the rotor flux variation by Eq. (14):

$\Delta \varphi_{r}=v_{r} \Delta T$.

In the proposed EDPC strategy, the generated active power and the local reactive power compensation will be estimated using rotor currents and the grid voltage components in the $d-q$ synchronous frame $\left(i_{r d}, i_{r q}\right.$ and $\left.V_{s}\right)$ and the synchronous pulsation $\left(\omega_{s}\right)$, as described in Eq. (15) [25]:

$$
\left\{\begin{array}{l}
P_{s}=-\frac{M}{L_{s}} V_{s} i_{r q} \\
Q_{A C}=\left[\frac{V_{s}^{2}}{L_{s} \omega_{s}}-V_{s} \frac{M}{L_{s}} i_{r d}\right] .
\end{array}\right.
$$

In the other hand, the rotor flux is estimated in $d-q$ synchronous frame as described in Eq. (16):

$$
\left\{\begin{array}{l}
\varphi_{r d}=\left(1-\frac{M^{2}}{L_{s} L_{r}}\right) L_{r} i_{r d}+\frac{M}{L_{s}} \frac{V_{s}}{\omega_{s}} \\
\varphi_{r d}=\left(1-\frac{M^{2}}{L_{s} L_{r}}\right) L_{r} i_{r q}
\end{array} .\right.
$$

Then the transformation $d q / \alpha \beta$ will give the rotor flux components in $\alpha-\beta$ rotor frame where the rotor flux angle $\delta_{r}$ is the angle between the $\varphi_{r \alpha}$ component and the roto flux vector, this angle will be used to determine the sector number of the rotor flux, as given in Eq. (17):

$\delta_{r}=\tan ^{-1}\left(\frac{\varphi_{r \beta}}{\varphi_{r \alpha}}\right)$.

Finally, we conclude that the variations of generated power and local reactive power compensation depend on the selected rotor voltage vector and its application time. Therefore, the good performances of the control depend on the rotor voltage selection that has a direct influence on the rotor flux variation; this latter has a proportional relationship with the generated active power and the local reactive power compensation. In this context, we use a switching table that is based on the rotor flux position instead of the stator flux position.

The active and reactive power errors are digitalized using respectively three and two-level hysteresis bands. The rotor flux space is divided into six sectors of $60^{\circ}$ each, as given in Fig. 3. Based on the outputs active and reactive powers hysteresis bands and rotor flux sector, the switching vector of voltage source inverter (VSI) is selected based on the switching table given in Table 1 .

\section{Simulation results}

The proposed DPC strategy is applied to DFIG driven by WT and operating under random wind speed profile and variable requested local reactive power compensation. The simulation has been performed in MATLAB/ Simulink environment, to verify the effectiveness and the robustness of the improved control strategy, the system parameters can be found in Table 2 [28].

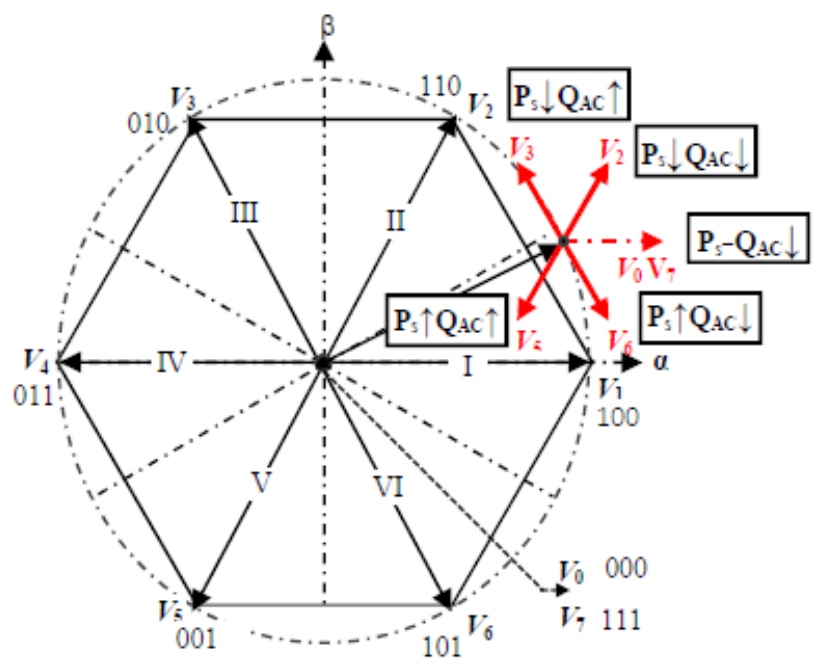

Fig. 3 Rotor voltage vectors and powers control

Table 1 EDPC Switching table

\begin{tabular}{cccccccc}
\hline \multirow{2}{*}{ HQs } & \multirow{2}{*}{ HPs } & & \multicolumn{5}{c}{$\mathrm{N}$} \\
& & I & II & III & IV & V & VI \\
\hline+1 & +1 & $V_{5}$ & $V_{6}$ & $V_{1}$ & $V_{2}$ & $V_{3}$ & $V_{4}$ \\
& 0 & $V_{7}$ & $V_{0}$ & $V_{7}$ & $V_{0}$ & $V_{7}$ & $V_{0}$ \\
& -1 & $V_{3}$ & $V_{4}$ & $V_{5}$ & $V_{6}$ & $V_{1}$ & $V_{2}$ \\
-1 & +1 & $V_{6}$ & $V_{1}$ & $V_{2}$ & $V_{3}$ & $V_{4}$ & $V_{5}$ \\
& 0 & $V_{0}$ & $V_{7}$ & $V_{0}$ & $V_{7}$ & $V_{0}$ & $V_{7}$ \\
& -1 & $V_{2}$ & $V_{3}$ & $V_{4}$ & $V_{5}$ & $V_{6}$ & $V_{1}$ \\
\hline
\end{tabular}


Table 2 WT-DFIG system parameters [28]

\begin{tabular}{lccc}
\hline Parameter & Value & Parameter & Value \\
\hline Rated Power $(\mathrm{kW})$ & 7.5 & $L_{r}(\mathrm{H})$ & 0.081 \\
Frequency $(\mathrm{Hz})$ & 50 & $M(\mathrm{H})$ & 0.0664 \\
Pole (pairs) & 3 & $R_{t}(\mathrm{~m})$ & 3.24 \\
$R_{s}(\Omega)$ & 1.02 & $G$ & 5.065 \\
$L_{s}(\mathrm{H})$ & 0.093 & $\rho\left(\mathrm{kg} / \mathrm{m}^{3}\right)$ & 1.125 \\
\hline
\end{tabular}

The active power reference is determined directly from the generated WT mechanical power, taking into account the DFIG efficiency. The random wind speed profile and the mechanical speed of DFIG are illustrated in Figs. 4 and 5. The mechanical DFIG speed varies according to the wind speed variations, this gives the three operation modes of DFIG: sub synchronous operation (Mode I), super synchronous operation (Mode II) and synchronous operation (Mode III), but when over speed occurs (Mode IV) the power is limited to its maximum value. The power coefficient, the speed ratio and the blade angle responses take different values in this range of time (over speed), as shown in Figs. 6 and 7.

The Figs. 8 and 9 show the generated active power and the local reactive power compensation responses. They follow their references values, the generated active power has always a negative sign, which means supplying always the AC grid, three operation modes of WT-DFIG can clearly be identified: the slip is positive in the sub-synchronous mode, it is null in the synchronous mode and it has a negative sign in the super-synchronous mode as shown in Fig. 10.

The mechanical slip is kept constant at the maximum value of $(-0.452)$ at over speed operation, where the system works in the third zone under the pitch angle control instead of the MPPT control. The local reactive power compensation has different sign, it is able to take or deliver the reactive power even it can operate to impose a unit power factor, according to the AC grid request, making the whole system operates as a local reactive power compensator in all operation modes.

The stator and rotor currents have variable amplitudes according to the wind speed variations; moreover, the stator currents frequency is maintained constant $(50 \mathrm{~Hz})$ as shown in Fig. 11, while the rotor currents frequency is related to the slip variation. In the sub and super-synchronous modes, the currents have sinusoidal evolution with variable frequency but in synchronous mode, the current has a direct evolution (direct current DC), as presented in Fig. 12. The rotor active power response analysis, under each operating mode, indicates generator behavior.

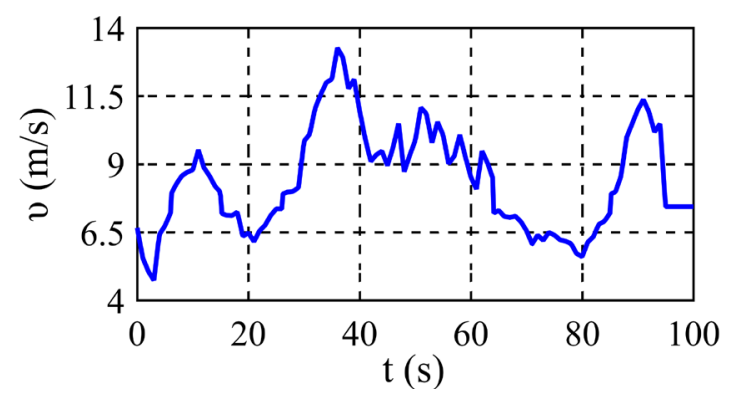

Fig. 4 Wind speed profile

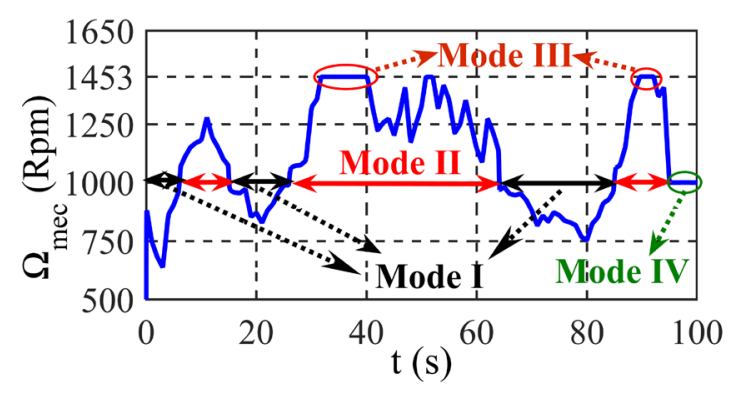

Fig. 5 DFIG mechanical speed

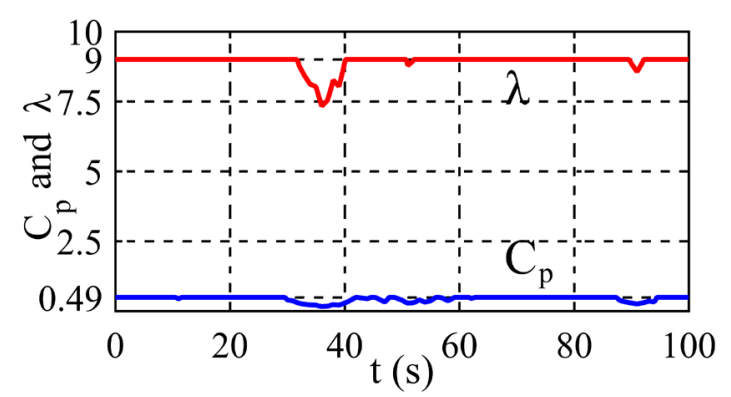

Fig. 6 Power coefficient and speed ratio

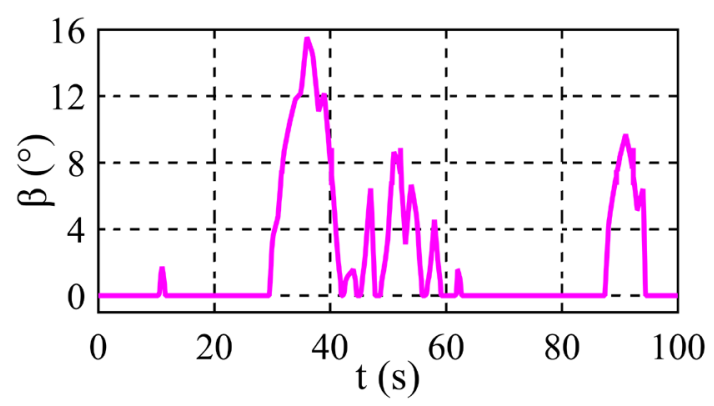

Fig. 7 Wind turbine blade angle

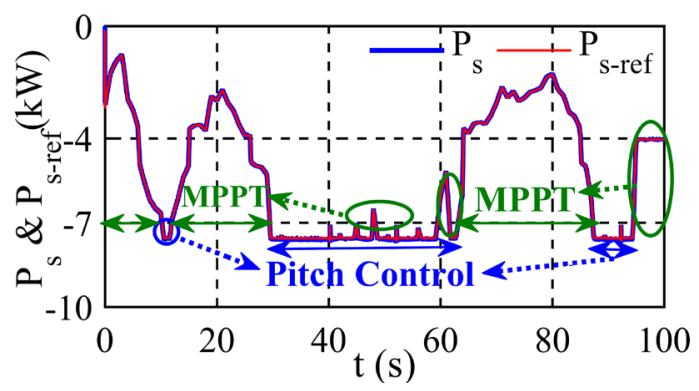

Fig. 8 Generated stator active power and its reference 


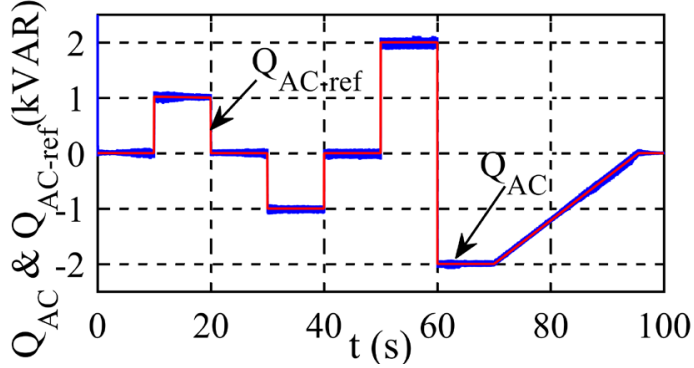

Fig. 9 Local reactive power compensation and its reference

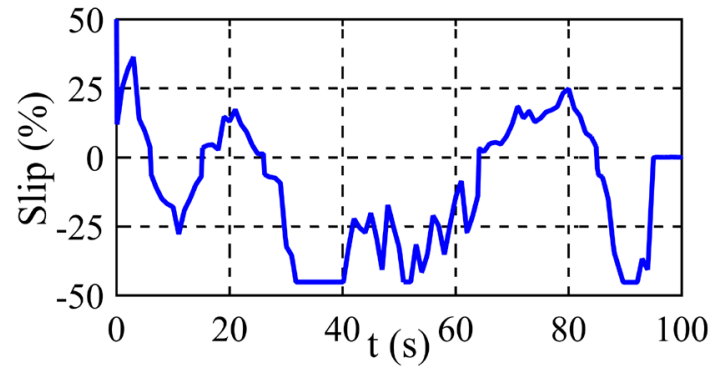

(a)

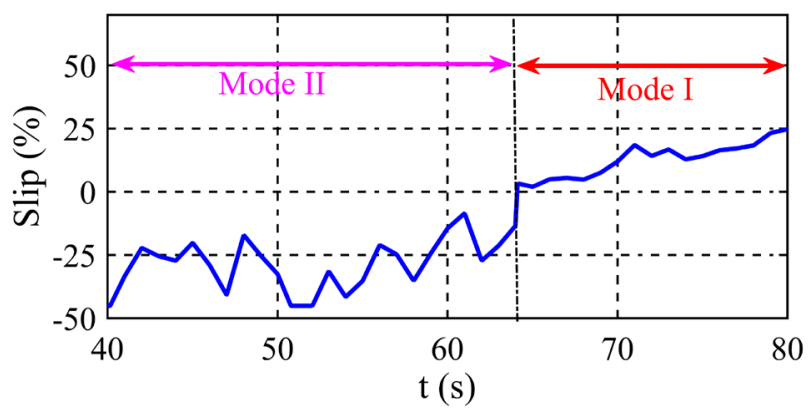

(b)

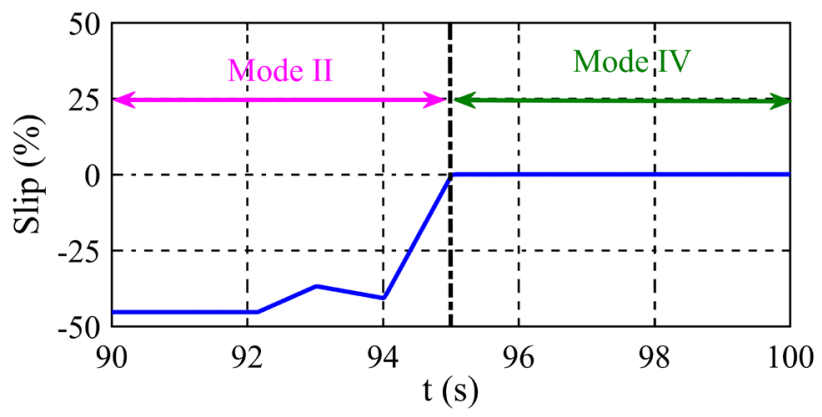

(c)

Fig. 10 (a) Evolution of mechanical slip and its zooms; (b) passage from the super-synchronous operation (Mode II) to the sub-synchronous operation (Mode I), (c) passage from the super-synchronous operation (Mode II) to the synchronous operation (Mode IV)

In sub-synchronous and synchronous mode, the generator absorbs power from the AC grid by the rotor, as presented in Fig. 13. It has a positive value in the sub-synchronous mode with small and constant magnitude in the synchronous mode due to the rotor resistances.

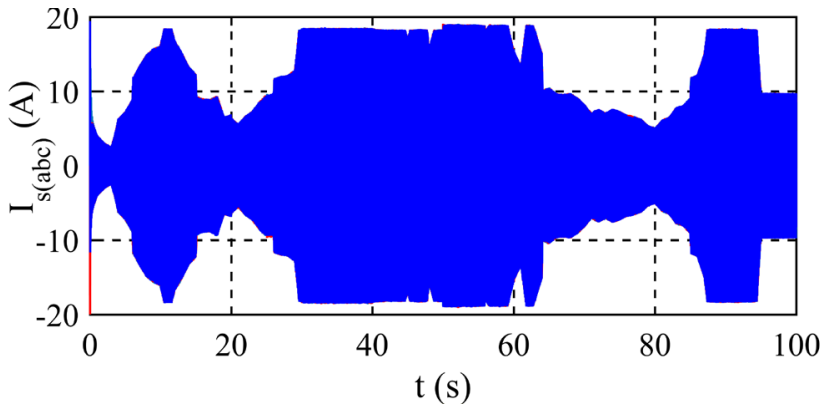

(a)

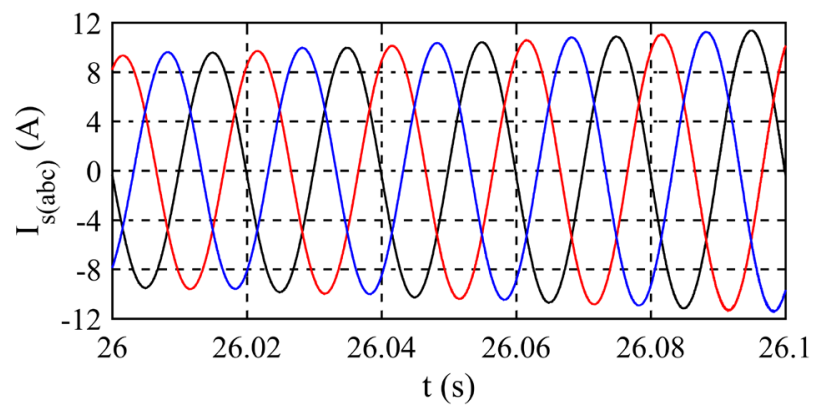

(b)

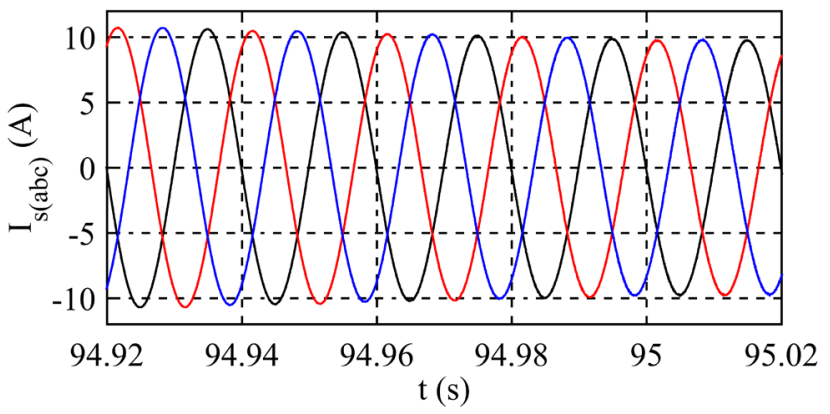

(c)

Fig. 11 (a) Generated phases stator current and its zooms, (b) passage from the super-synchronous mode to the sub-synchronous mode; (c) passage from the super-synchronous mode to the synchronous mode

In super-synchronous mode, the rotor power has a negative sign with constant maximum amplitude during overspeed operation mode.

The generator delivers power by both stator and rotor in this mode. Whereas, the rotor reactive power has changed according to the operation modes, it is null in the synchronous mode, as illustrated in Fig. 14.

The electromagnetic torque response is shown in Fig. 15; it has the same behavior that the generated active powers, with a negative sign in all operation modes.

As mentioned above, the DFIG supply directly the AC grid by its stator, so it is necessary to maintain the quality norms. In this context, a Fast Fourier Transform (FFT) analysis of the generated AC grid currents is carried out and presented in Fig. 16. 


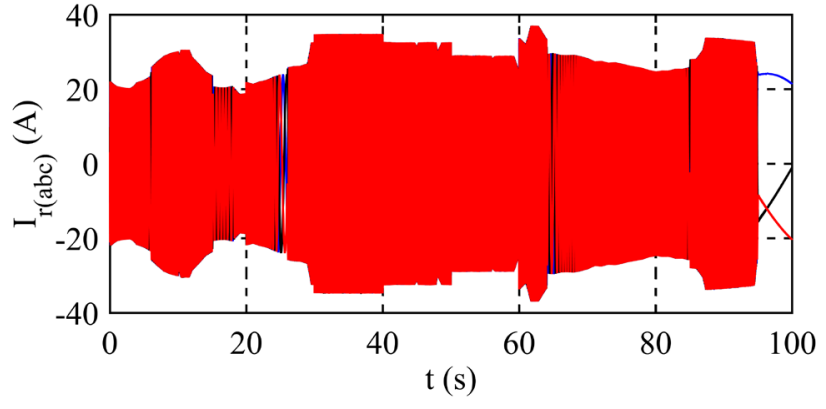

(a)

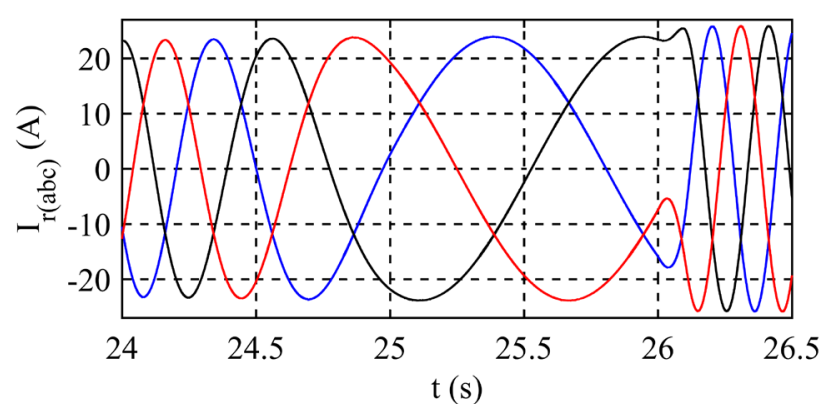

(b)

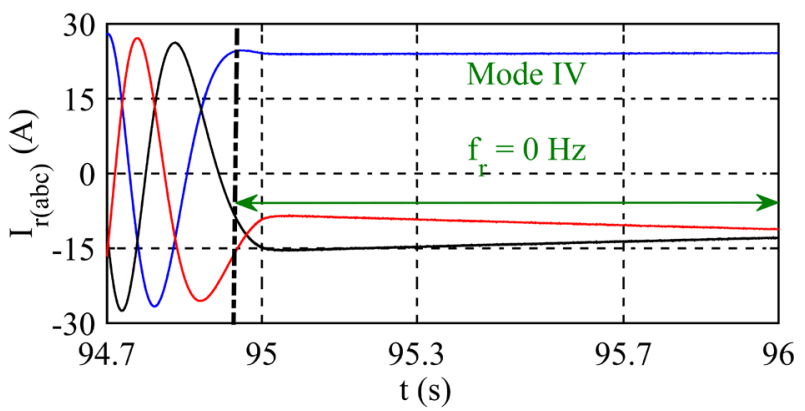

(c)

Fig. 12 (a) Rotor phases current and its zooms; (b) passage from the super-synchronous mode to the sub-synchronous mode; (c) passage

from the super-synchronous mode to the synchronous mode

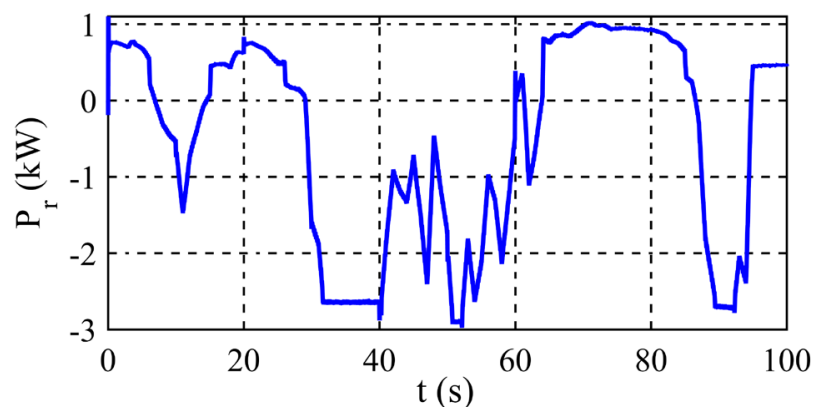

Fig. 13 The rotor's power waveform

The harmonic spectrum has a THD of $0.65 \%$ for the sub-synchronous operating mode, $0.32 \%$ for the super-synchronous mode, $0.36 \%$ for the over-speed and $0.30 \%$ for the synchronous mode. The THDs of the generated currents are lower than $0.66 \%$, which is much lower

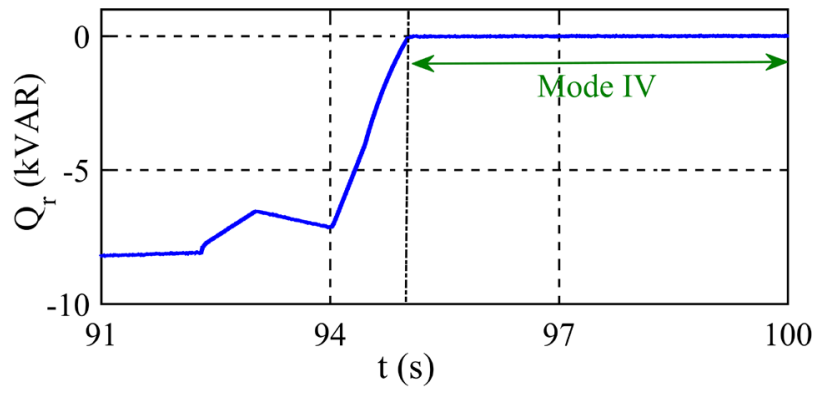

Fig. 14 Zoom of rotor reactive power in synchronous mode

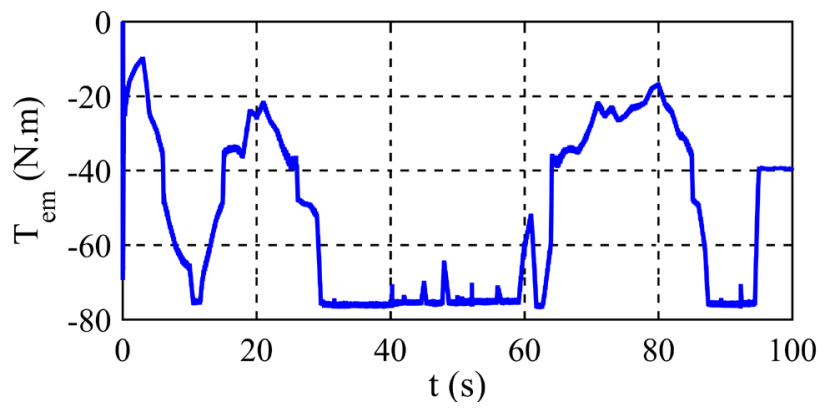

(a)

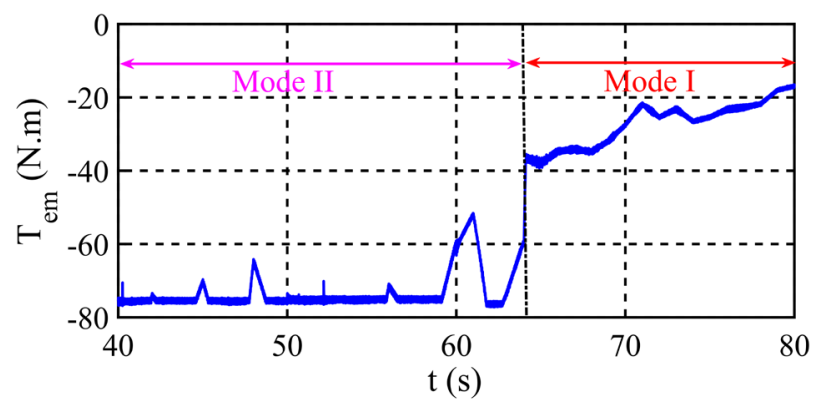

(b)

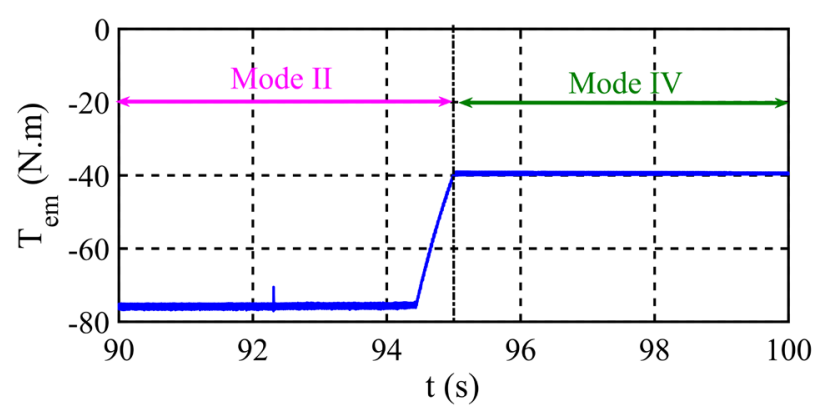

(c)

Fig. 15 (a) Generator electromagnetic torque; (b) zoom of passage from the super-synchronous operation (Mode II) to the sub-synchronous operation (Mode I), (c) zoom of passage from the super-synchronous

operation (Mode II) to the synchronous operation (Mode IV)

than the limits imposed by IEEE Std $519(<5 \%)$, under all operating modes even under the pitch angle control (overspeed), this confirms the good performances, the high control precision and well power quality of the proposed control strategy. 

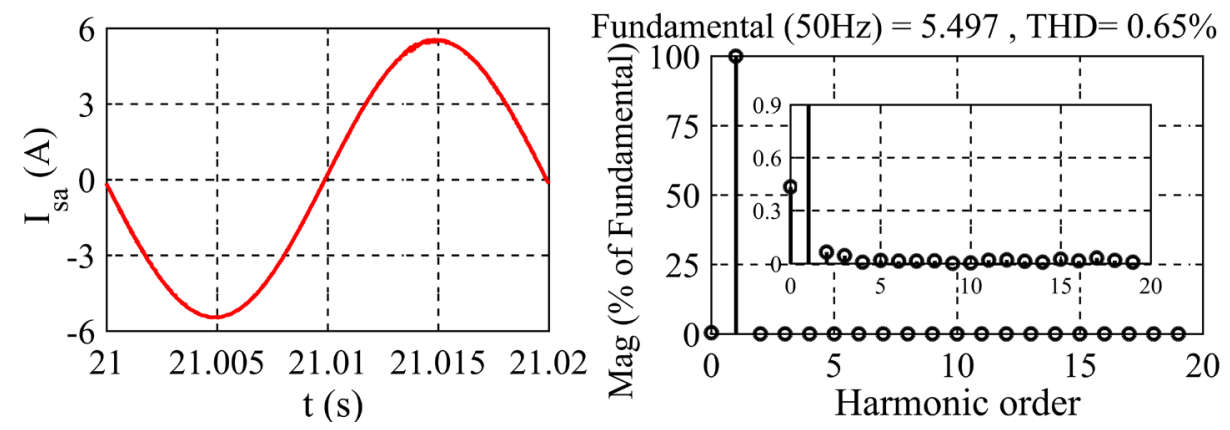

(a)

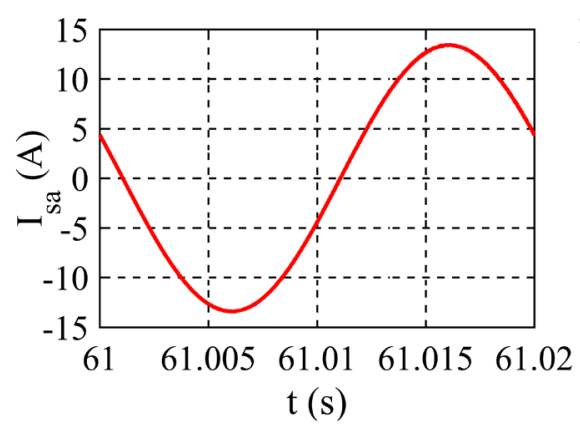

Fundamental $(50 \mathrm{~Hz})=13.41, \mathrm{THD}=0.32 \%$

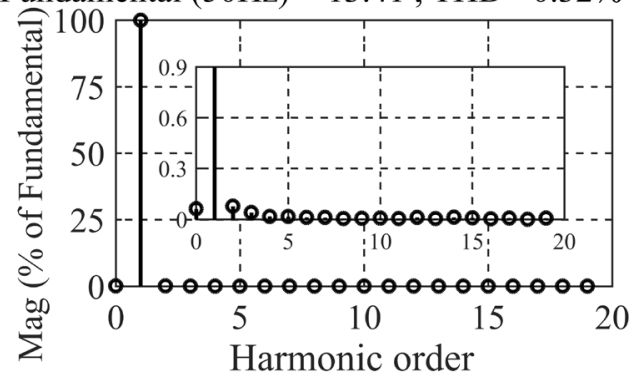

(b)
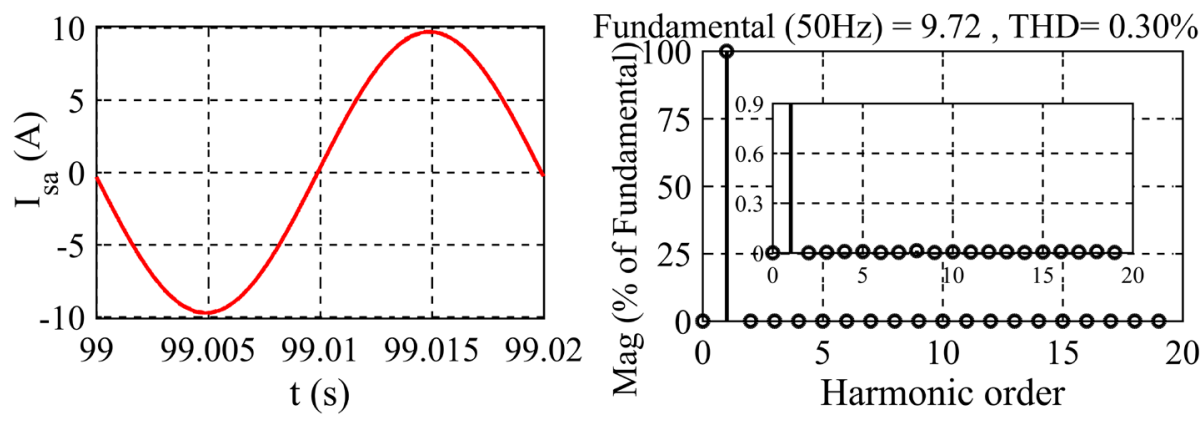

(c)
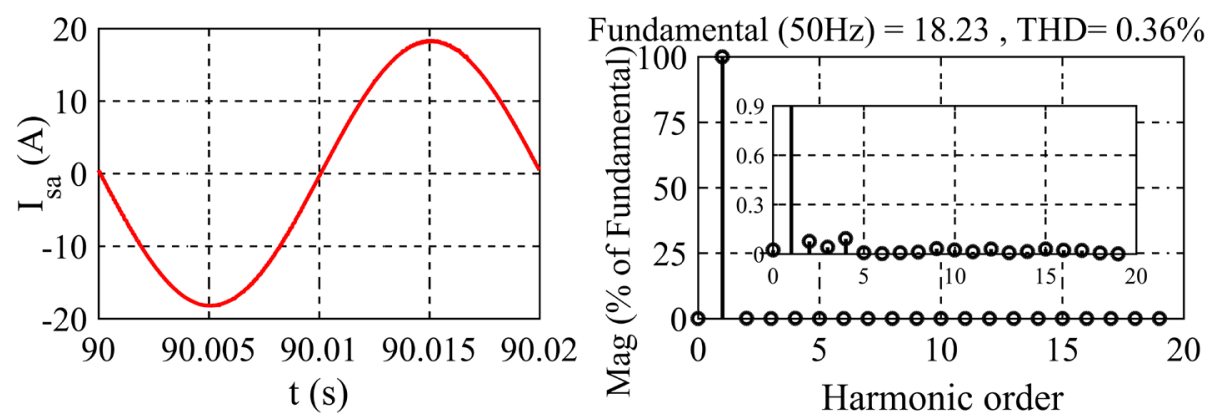

(d)

Fig. 16 Stator current and harmonic spectrum, for all operation modes; (a) Sub-synchronous operation ((Mode I); (b) Super-Synchronous operation ((Mode II); (c) Synchronous operation ((Mode III); (d) Over-speed operation ((Mode IV)

\section{Conclusion}

In this paper, an Enhanced DPC strategy is applied to a WT-DFIG system operating under random behavior conditions regarding wind speed and required locale reactive power compensation profiles. All WT-DFIG operation modes (sub, super, synchronous and the over speed) have been treated in successive and continuous manner. The simulation results showed good performances, the active power and locale reactive power compensation have tracked their reference values with low ripples rate. 
The generated currents kept sinusoidal waveform with constant frequency and the FFT analysis has indicated lower THD, below the limits imposed by IEEE Std 519.

This strategy has proved its merit and robustness, where the simplicity of control is conserved, the wind power is optimized, the high powers control precision is observed, the good current quality injected to the AC grid is provided, the satisfactory compensation of local reactive power according to the AC grid demand is respected and above all DFIG's advantages are exploited under variable conditions. This strategy has proved its merit and robustness, where the simplicity of control is conserved, the wind power is optimized, the high powers control precision is observed, and the good current quality injected to the AC grid is provided.

\section{Nomenclature}

$\begin{array}{ll}v & \text { Wind speed } \\ P_{\text {mec }} & \text { Mechanical power } \\ \Omega_{t} & \text { Turbine rotation speed } \\ \Omega_{\text {mec }} & \text { DFIG rotation speed } \\ \rho & \text { Air density } \\ R_{t} & \text { WT blade radius } \\ C_{p} & \text { Power coefficient } \\ \lambda & \text { Speed ration } \\ G & \text { Gearbox gain } \\ \beta & \text { WT blade angle } \\ P_{s} & \text { Generated active power } \\ P_{r} & \text { Rotor active power } \\ P_{n} & \text { Nominal power of the DFIG and the WT } \\ P_{\text {max }} & \text { Maximum generated active power } \\ p & \text { Pair poles number of the DFIG } \\ Q_{r} & \text { Rotor reactive power } \\ Q_{A C} & \text { Local AC grid reactive power } \\ C_{i} & \text { Turbine constants, i: [1...6] } \\ \text { THD } & \text { Total Harmonic Distortion }\end{array}$

$\delta_{r} \quad$ Angle between the $\alpha$ and $\beta$ rotor flux components

$\gamma \quad$ Angle between the rotor and stator flux
$V_{s}, V_{r} \quad$ Grid and rotor voltage

$I_{s}, I_{r} \quad$ Stator and rotor current

$V_{s d}, V_{s q}$ Stator voltages components in $d-q$ synchronous frame

$V_{s \alpha}, V_{s \beta}$ Stator voltages components in $\alpha-\beta$ rotor frame

$V_{r d}, V_{r q}$ Rotor voltages components in $d-q$ synchronous frame

$V_{r \alpha}, V_{r \beta}$ Rotor voltages components in $\alpha-\beta$ rotor frame

$I_{s d}, I_{s q} \quad$ Stator currents components in $d-q$ synchronous frame

$I_{s \alpha}, I_{s \beta} \quad$ Stator currents components in $\alpha-\beta$ rotor frame

$I_{r d}, I_{r q} \quad$ Rotor currents components in $d$ - $q$ synchronous frame

$I_{r \alpha}, I_{r \beta} \quad$ Rotor currents components in $\alpha-\beta$ rotor frame

$\varphi_{s d}, \varphi_{s q} \quad$ Stator flux components in $d-q$ synchronous frame

$\varphi_{r d}, \varphi_{r q} \quad$ Rotor flux components in $d-q$ synchronous frame

$\varphi_{s \alpha}, \varphi_{s \beta} \quad$ Stator flux components in $\alpha-\beta$ rotor frame

$\varphi_{r \alpha}, \varphi_{r \beta} \quad$ Rotor flux components in $\alpha-\beta$ rotor frame

$\varphi_{s}, \varphi_{r} \quad$ Stator and rotor flux

$\omega_{s}, \omega, \omega_{r}$ Grid, mechanical and rotor pulsations respectively

$R_{s}, R_{r} \quad$ Stator and rotor phase resistances

$L_{s}, L_{r} \quad$ Stator and rotor phase leakage inductances

$M \quad$ Stator-rotor mutual inductance.

$\theta_{r} \quad$ Angle between synchronous and rotor frame.

$\Delta T \quad$ Difference between two instants of time

\section{References}

[1] Landrigan, P. J., Fuller, R., Fisher, S., Suk, W. A., Sly, P., Chiles, T. C., Bose-O'Reilly, S. "Pollution and children's health", Science of The Total Environment, 650(2), pp. 2389-2394, 2019. https://oi.org/10.1016/j.scitotenv.2018.09.375

[2] Jaladi, K. K., Sandhu, K. S., Bommala, P. "Real-Time Simulator of DTC-FOC-Based DFIG During Voltage Dip and LVRT", Journal of Control, Automation and Electronical Systems, 31(2), pp. 402-411, 2020.

https://doi.org/10.1007/s40313-019-00557-9

[3] Shihabudheen, K. V., Pillai, G. N., Krishnama Raju, S. "Neuro-Fuzzy Control of DFIG Wind Energy System with Distribution Network", Electric Power Components Systems, 46(13), pp. 1416-1431, 2019. https://doi.org/10.1080/15325008.2018.1499154

[4] Fayssal, A., Chaiba, A., Babes, B., Mekhilef, S. "Design and implementation of high performance field oriented control for- grid-connected doubly fed induction generator via hysteresis rotor current controller", Revue Roumanie des Sciences Techniques - Serie Électrotechnique et Énergétique, 61(4), pp. 319-324, 2016.

[5] Prasad, R. M., Mulla, M. A. "Mathematical Modeling and PositionSensorless Algorithm for Stator-Side Field-Oriented Control of Rotor-Tied DFIG in Rotor Flux Reference Frame", IEEE Transactions on Energy Conversion, 35(2), pp. 631-639, 2020. https://doi.org/10.1109/TEC.2019.2956255

[6] Li, P., Wang, J., Wu, F., Li, H. "Nonlinear controller based on state feedback linearization for series-compensated DFIG-based wind power plants to mitigate sub-synchronous control interaction", International Transactions on Electrical Energy Systems, 29(1), Article number: e2682, 2019.

https://doi.org/10.1002/etep.2682 
[7] Cherif, B. D. E., Bendiabdellah, A., Bendjebbar, M., Tamer, A. "Neural Network Based Fault Diagnosis of Three Phase Inverter Fed Vector Control Induction Motor", Periodica Polytechnica Electrical Engineering and Computer Science, 63(4), pp. 295-305, 2019. https://doi.org/10.3311/PPee.14315

[8] Xu, L., Cartwright, P. "Direct active and reactive power control of DFIG for wind energy generation", IEEE Transactions on Energy Conversion, 21(3), pp. 750-758, 2006. https://doi.org/10.1109/TEC.2006.875472

[9] Zhang, Y., Jiao, J., Xu, D., Jiang, D., Wang, Z., Tong, C. "Model Predictive Direct Power Control of Doubly Fed Induction Generators Under Balanced and Unbalanced Network Conditions", IEEE Transactions on Industry Applications, 56(1), pp. 771-786, 2020. https://doi.org/10.1109/TIA.2019.2947396

[10] Ouchen, S., Steinhart, H., Benbouzid, M., Blaabjerg, F. "Robust DPC-SVM control strategy for shunt active power filter based on $\mathrm{H} \infty$ regulators", International Journal of Electrical Power \& Energy Systems, 117, Article number: 105699, 2020 https://doi.org/10.1016/j.ijepes.2019.105699

[11] Reguig Berra, A., Barkat, S., Bouzidi, M. "Virtual Flux Predictive Direct Power Control of Five-level T-type Multi-terminal VSCHVDC System", Periodica Polytechnica Electrical Engineering and Computer Science, 64(2), pp. 133-143, 2020. https://doi.org/10.3311/PPee.14441

[12] Debouza, M., Al-Durra, A., Errouissi, R., Muyeen, S. M. "Direct power control for grid-connected doubly fed induction generator using disturbance observe based control", Renewable Energy, 125, pp. 365-372, 2018.

https://doi.org/10.1016/j.renene.2018.02.121

[13] Fayssal, A., Chaiba, A. "A novel direct power control for grid-connected doubly fed induction generator based on hybrid artificial intelligent control with space vector modulation", Revue Roumanie des Sciences Techniques - Serie Électrotechnique et Énergétique, 61(3), pp. 263-268, 2016.

[14] Pichan, M., Rastegar, H., Monfared, M. "Two fuzzy-based direct power control strategies for doubly-fed induction generators in wind energy conversion systems", Energy, 51(1), pp. 154-162, 2013. https://doi.org/10.1016/j.energy.2012.12.047

[15] Boroujeni, H. Z., Othman, M. F., Shirdel, A. H., Rahmani, R., Movahedi, P., Toosi, E. S. "Improving waveform quality in direct power control of DFIG using fuzzy controller", Neural Computing and Applications, 26(4), pp. 949-955, 2015. https://doi.org/10.1007/s00521-014-1725-7

[16] Mehdi, A., Reama, A., Medouce, H. E., Rezgui, S. E., Benalla, H. "Direct active and reactive power control of DFIG based wind energy conversion system", In: 2014 International Symposium on Power Electronics, Electrical Drives, Automation and Motion, Ischia, Italy, 2014, pp. 1128-1133.

https://doi.org/10.1109/SPEEDAM.2014.6872091

[17] Verij Kazemi, M., Moradi, M., Verij Kazemi, R. "Fuzzy logic control to improve the performance of the direct power control based DFIG", COMPEL - The international journal for computation and mathematics in electrical and electronic engineering, 33(1-2), pp. 254-272, 2014.

https://doi.org/10.1108/COMPEL-08-2012-0131
[18] Tamalouzt, S. "Performances of direct reactive power control technique applied to three level-inverter under random behavior of wind speed", Revue Roumanie des Sciences Techniques - Serie Électrotechnique et Énergétique, 64(1), pp. 33-38, 2019.

[19] Benbouhenni, H. "Application of Five-Level NPC Inverter in DPC ANN of Doubly Fed Induction Generator for Wind Power Generation Systems", International Journal of Smart Grid - ijSmartGrid, 3(3), pp. 128-137, 2019.

[20] Yousefi-Talouki, A., Pouresmaeil, E., Nørregaard Jørgensen, B. "Active and reactive power ripple minimization in direct power control of matrix converter-fed DFIG", International Journal of Electrical Power \& Energy Systems, 63, pp. 600-608, 2014. https://doi.org/10.1016/j.ijepes.2014.06.041

[21] Lhachimi, H., Sayouti, Y., El Kouari, Y. "Optimal improvement of direct power control strategy based on sliding mode controllers", Computers \& Electrical Engineering, 71, pp. 637-656, 2018. https://doi.org/10.1016/j.compeleceng.2018.08.013

[22] Amrane, F., Chaiba, A., Mekhilef, S. "High performances of Grid-connected DFIG based on Direct Power Control with Fixed Switching Frequency via MPPT Strategy using MRAC and Neuro-Fuzzy Control", Journal of Power of Technologies, 96(1), pp. 27-39, 2016.

[23] Farshadnia, M., Taher, S. A. "Current-based direct power control of a DFIG under unbalanced grid voltage", International Journal of Electrical Power \& Energy Systems, 62, pp. 571-582, 2014. https://doi.org/10.1016/j.ijepes.2014.05.009

[24] Zandzadeh, M. J., Vahedi, A. "Modeling and improvement of direct power control of DFIG under unbalanced grid voltage condition", International Journal of Electrical Power \& Energy Systems, 59, pp. 58-65, 2014. https://doi.org/10.1016/j.ijepes.2014.01.022

[25] Mazouz, F., Belkacem, S., Colak, I., Drid, S., Harbouche, Y. "Adaptive direct power control for double fed induction generator used in wind turbine", International Journal of Electrical Power \& Energy Systems, 114, Article number: 105395, 2020. https://doi.org/10.1016/j.ijepes.2019.105395

[26] Tamalouzt, S., Idjdarene, K., Rekioua, T., Abdessemed, R. "Direct torque control of wind turbine driven doubly fed induction generator", Revue Roumanie des Sciences Techniques - Serie Électrotechnique et Énergétique, 61(3), pp. 244-249, 2016.

[27] Sun, D., Wang, X., Nian, H., Zhu, Z. Q. "A Sliding-Mode Direct Power Control Strategy for DFIG Under Both Balanced and Unbalanced Grid Conditions Using Extended Active Power", IEEE Transactions on Power Electronic, 33(2), pp. 1313-1322, 2018. https://doi.org/10.1109/TPEL.2017.2686980

[28] Tamalouzt, S., Benyahia, N., Rekioua, T., Rekioua, D., Abdessemed, R. "Performances analysis of WT-DFIG with PV and fuel cell hybrid power sources system associated with hydrogen storage hybrid energy system", International Journal of Hydrogen Energy, 41(45), pp. 21006-21021, 2016. https://doi.org/10.1016/j.ijhydene.2016.06.163

[29] Lalouni, S., Rekioua, D., Idjdarene, K., Tounzi. A. "Maximum Power Point Tracking Based Hybrid Hill-climb Search Method Applied to Wind Energy Conversion System", Electric Power Components and Systems, 43(8-10), pp. 1028-1038, 2015. https://doi.org/10.1080/15325008.2014.999143 